\title{
Reduction of Nitroarenes to Azoxybenzenes by Potassium Borohydride in Water
}

\author{
Yufang Liu ${ }^{1}$, Bo Liu ${ }^{2, *}$, Ailing Guo ${ }^{1}$, Zhenming Dong ${ }^{1}$, Shuo Jin ${ }^{1}$ and Yun Lu ${ }^{3}$ \\ 1 School of Chemistry and Chemical Engineering, Shanxi University, Taiyuan 030006, China \\ 2 School of Science, Beijing Jiaotong University, Beijing 100044, China \\ 3 Department of Chemistry, Southern Illinois University Edwardsville, Edwardsville, IL 62026, USA \\ * Author to whom correspondence should be addressed; E-Mail: boliu413@yahoo.com.cn; \\ Tel.: +86-10-51688409; Fax: +86-10-51688497.
}

Received: 24 February 2011; in revised form: 15 April 2011 / Accepted: 22 April 2011 /

Published: 28 April 2011

\begin{abstract}
The synthesis of the azoxybenzenes by the reduction of nitroarenes with reducing agent potassium borohydride in water was reported for the first time. PEG-400 was used as a phase transfer catalyst and could effectively catalyze the reduction. The electronic effects of substituent groups play an important role in determining the reduction efficiencies. Electron-withdrawing substituents promote the formation of the azoxybenzene products, while electron-releasing groups retard the reductions to various degrees depending on the extent of their electron-donating ability.
\end{abstract}

Keywords: nitroarenes; azoxybenzenes; potassium borohydride; water; PEG-400

\section{Introduction}

In 1956, Weill and Panson obtained azoxybenzene from the reduction of nitrobenzene by sodium borohydride in diglyme [1]. Since then, a few investigations on the reduction of nitroarenes by borohydrides were reported [2-7]. The reducing agents and the reaction media used include sodium borohydride in dimethyl sulfoxide or sulfolane [2], potassium borohydride in ethanol or pyridine [3], $\mathrm{NaBH}_{4}-\mathrm{BiCl}_{3}$ in methanol [4], $\mathrm{NaBH}_{4}-\mathrm{Bi}$ in ethanol [5,6], and $\mathrm{NaBH}_{4}-(\mathrm{PhTe})_{2}$ in ethanol [7]. In addition to azoxybenzenes, further reduction products of azobenzenes were sometimes produced depending upon the reaction conditions used. Note that all of these reactions took place in pure organic 
solvents. Some of them even required pure heavy metals or their compounds as catalyst. This increased both the cost and environmental pollution when using these reactions to synthesize azoxybenzenes. Performing the reduction using a non-toxic borohydride reducing agent in aqueous solution is thus desirable. Herein we reported for the first time the synthesis of the azoxybenzenes by the reduction of nitroarenes by potassium borohydride in aqueous solution (Scheme 1). Poly(ethylene glycol)-400 (PEG-400) was used as a phase transfer catalyst. PEG catalysts have many favorable properties, such as wide availability, low price, nontoxicity, biodegradability, thermal stability, and water solubility. Moreover, their properties can be varied by changing molecular weights. These properties have empowered PEGs as useful phase transfer catalysts in chemical synthesis [8-12].

Scheme 1. Reduction of nitroarenes to azoxybenzenes.

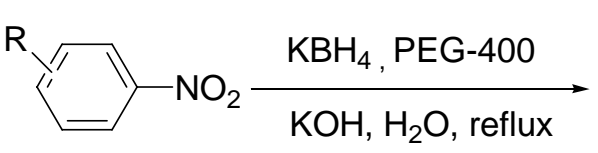

1

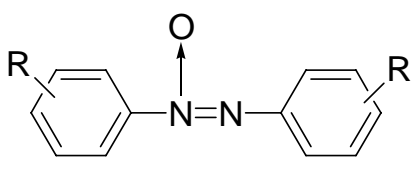

2

\section{Results and Discussion}

Taking the reduction of $m$-chloronitrobenzene as an example, the effect of the PEG catalysts of various molecular weights on the efficiency of the reaction was investigated. The reactions were performed using $2 \mathrm{mmol}$ nitroarene and $16 \mathrm{mmol}$ potassium borohydride in $20 \mathrm{~mL}$ aqueous solution with $2 \%(\mathrm{w} / \mathrm{w})$ of $\mathrm{KOH}$ at reflux temperature conditions. The results are listed in Table 1.

First, we investigated the reduction with or without the presence of the PEG-400 (entries 1-1 and 1-2). The results showed that, with PEG-400, the reaction time was significantly shortened ( $3 \mathrm{~h}$ vs. $23 \mathrm{~h}$ ) and reaction yield was greatly enhanced (85\% vs. 52\%), suggesting that PEG-400 could efficiently catalyze the reduction. This may be because PEG-400 could form a crown ether type complex with the $\mathrm{K}^{+}$in $\mathrm{KBH}_{4}$ as shown in Scheme 2, which then brings the $\mathrm{BH}_{4}{ }^{-}$reducing species into the organic phase of the oily $m$-chloronitrobenzene (under refluxing conditions, it is in a melted state) for the redox reaction to take place $[13,14]$. Therefore, the PEG acts as a phase transfer catalyst. Moreover, the effects of various kinds of PEG's, PEG-600, PEG-800 and PEG-1000 in the reduction reactions were also investigated (entries 1-3 to 1-5). Results showed that increasing molecular weights of PEGs do not affect the reduction efficiency.

Table 1. Effects of PEGs on the reduction reaction of $m$-chloronitrobenzene.

\begin{tabular}{cccc}
\hline Entry & Catalyst $^{\text {a }}$ & Reaction time (h) & Yield (\%) $^{\mathbf{b}}$ \\
\hline $1-1$ & 0 & 23 & 52 \\
$1-2$ & PEG-400 & 3 & 85 \\
$1-3$ & PEG-600 & 3 & 85 \\
$1-4$ & PEG-800 & 3 & 85 \\
$1-5$ & PEG-1000 & 3 & 85 \\
\hline
\end{tabular}

${ }^{\mathrm{a}}$ The amount of the catalyst is $1 \mathrm{mmol} ;{ }^{\mathrm{b}}$ Isolated yields of $m, m^{\prime}$-dichloroazoxybenzene after recrystallization in ethanol. 
Scheme 2. The formation of the PEG-KBH 4 complex $[13,14]$.

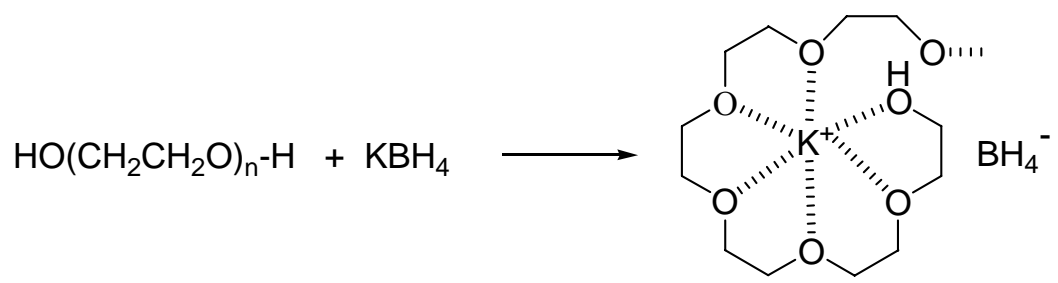

The reductions of several nitroarenes 1a-1 by potassium borohydride were studied in water catalyzed by PEG-400 at reflux temperature, and the corresponding azoxybenzenes 2a-i were produced in good yields, but the azoxybenzenes $\mathbf{2} \mathbf{j}-\mathbf{I}$ were not obtained (Table 2). The results suggested that the electronic effects of substituent groups play an important role in determining the reduction efficiencies. It appears that electron-withdrawing substituents promote the formation of the azoxybenzene products, while the electron-releasing substituents retard the reduction to various degrees, depending upon their electron-donating ability. In addition, we found that the reactions of $o$-chloronitrobenzene, $o$-bromonitrobenzene and $o$-iodonitrobenzene gave very complicated mixtures which are difficult to separate (not listed in Table 2, detailed studies are under way).

Table 2. Reductions of nitroarenes into the corresponding azoxybenzenes by potassium borohydride in water catalyzed by PEG-400 at refluxing temperature ${ }^{\mathrm{a}}$.

\begin{tabular}{|c|c|c|c|c|c|c|}
\hline Entry & $\mathbf{R}$ & Nitroarenes & m. p. $\left({ }^{\circ} \mathrm{C}\right)^{\mathrm{b}}$ & Reaction time (h) & Products & Yield (\%) $^{c}$ \\
\hline $2-1$ & $m-\mathrm{Cl}$ & $1 a$ & $43-45$ & 3 & $2 \mathbf{a}$ & 85 \\
\hline $2-2$ & $p-\mathrm{Cl}$ & $1 b$ & $81-83$ & 5 & $2 \mathbf{b}$ & 78 \\
\hline $2-3$ & $m-\mathrm{Br}$ & 1c & $56-58$ & 2 & $2 c$ & 84 \\
\hline $2-4$ & $m-\mathrm{I}$ & $1 d$ & $36-38$ & 3 & $2 d$ & 80 \\
\hline $2-5$ & $p-\mathrm{Br}$ & 1e & $125-127$ & 10 & $2 \mathbf{e}$ & 14 \\
\hline $2-6$ & $p-\mathrm{Br}$ & $1 e$ & $125-127$ & 4 & $2 e$ & $79^{d}$ \\
\hline $2-7$ & $p$-I & 1f & $171-173$ & 10 & $2 f$ & 16 \\
\hline $2-8$ & $p-\mathrm{I}$ & 1f & $171-173$ & 4 & $2 f$ & $76^{\mathrm{d}}$ \\
\hline $2-9$ & $p-\mathrm{COOH}$ & $1 g$ & $239-241$ & 2 & $2 g$ & 92 \\
\hline $2-10$ & $\mathrm{H}$ & $1 \mathrm{~h}$ & 5.7 & 4 & $2 \mathbf{h}$ & 61 \\
\hline $2-11$ & $m-\mathrm{CH}_{3}$ & $\mathbf{1 i}$ & 16 & 10 & $2 \mathbf{i}$ & 50 \\
\hline $2-12$ & $o-\mathrm{CH}_{3}$ & $\mathbf{1 j}$ & -9.5 & 24 & NR & 0 \\
\hline $2-13$ & $p-\mathrm{CH}_{3}$ & $1 k$ & $51-52$ & 24 & NR & 0 \\
\hline $2-14$ & $p-\mathrm{OCH}_{3}$ & 11 & $51-53$ & 24 & NR & 0 \\
\hline
\end{tabular}

The water-soluble $p$-nitrobenzoic acid (entry 2-9) could react without the presence of the PEG-400, and the reaction results are almost the same as with the PEG. This is because the reaction system is homogeneous and the phase transfer catalyst is not necessary. $p$-Bromonitrobenzene and $p$-iodonitrobenzene, whose melting points are higher than $100^{\circ} \mathrm{C}$, exist in solid state in the reaction system. As expected, the reductions were observed to be much less efficient than the reactions with nitroarenes 
of melting points lower than $100{ }^{\circ} \mathrm{C}$ (entries 2-5 and 2-7). In these cases, the phase transfer catalyst did not work. We thus added ethanol to the aqueous solutions of these reactions $(50 \%: 50 \%, \mathrm{v} / \mathrm{v})$ in order to enhance the solubility of the substrates, and the reductions were observed to take place efficiently (entries 2-6 and 2-8).

\section{Experimental}

\subsection{General}

All the reagents were obtained from commercial sources and used without further purification. Melting points of the compounds were measured using a Sanyo-Gallenksmp apparatus and were uncorrected. The IR spectra were recorded on a Perkin-Elmer 1700 spectrometer. ${ }^{1} \mathrm{H}-\mathrm{NMR}$ spectra were recorded on a Bruker DLX $300 \mathrm{MHz}$ spectrophotometer. Elemental analysis was obtained from a VazioE elemental analyzer.

\subsection{General Synthetic Procedure}

Potassium borohydride (16 mmol), PEG-400 (1 mmol) and nitroarenes $(2 \mathrm{mmol})$ were added in turn to $20 \mathrm{~mL}$ aqueous solution with $2 \%(\mathrm{w} / \mathrm{w}) \mathrm{KOH}$ in a flask equipped with a condenser. The resulting solutions were magnetically stirred at reflux temperature for a certain period of time until the nitroarenes were consumed. The consumption of the nitroarenes was monitored by TLC. Upon cooling, the mixture was poured into a slurry of concentrated hydrochloric acid and ice. The precipitated product was filtered, washed, dried, and recrystallized.

m,m'-Dichloroazoxybenzene (2a). Recrystallized from ethanol, m,p. 97-98 ${ }^{\circ} \mathrm{C}$ (lit. [15] 96-97 ${ }^{\circ} \mathrm{C}$ ); ${ }^{1} \mathrm{H}-$ NMR $\left(\mathrm{CDCl}_{3}\right): \delta 7.36-7.56(\mathrm{~m}, 4 \mathrm{H}), 7.99(\mathrm{~d}, J=7.5 \mathrm{~Hz}, 1 \mathrm{H}), 8.19(\mathrm{~d}, J=8.4 \mathrm{~Hz}, 1 \mathrm{H}), 8.25(\mathrm{~s}, 1 \mathrm{H})$, 8.30 (s, 1H); IR, v (KBr disc): 1556, 1470, 1421, 1302, $783 \mathrm{~cm}^{-1}$.

p,p’-Dichloroazoxybenzene (2b). Recrystallized from ethanol, m.p. 154-156 ${ }^{\circ} \mathrm{C}$ (lit. [15] 156-157 ${ }^{\circ} \mathrm{C}$ ); ${ }^{1} \mathrm{H}-\mathrm{NMR}\left(\mathrm{CDCl}_{3}\right): \delta 7.47-7.53(\mathrm{~m}, 4 \mathrm{H}), 8.19(\mathrm{~d}, J=8.7 \mathrm{~Hz}, 2 \mathrm{H}), 8.28(\mathrm{~d}, J=9 \mathrm{~Hz}, 2 \mathrm{H}) ; \mathrm{IR}, v(\mathrm{KBr}$ disc): $1583,1481,1404,1323,831 \mathrm{~cm}^{-1}$.

m,m'-Dibromoazoxybenzene (2c). Recrystallized from ethanol, m.p. 111-113 ${ }^{\circ} \mathrm{C}$ (lit. [15] 109-110 ${ }^{\circ} \mathrm{C}$ ); ${ }^{1} \mathrm{H}-\mathrm{NMR}\left(\mathrm{CDCl}_{3}\right): \delta$ 7.36-7.45 (m, 2H), $7.56(\mathrm{~d}, J=9.9 \mathrm{~Hz}, 1 \mathrm{H}), 7.73(\mathrm{~d}, J=9.9 \mathrm{~Hz}, 1 \mathrm{H}), 8.06(\mathrm{~d}$, $J=0.9 \mathrm{~Hz}, 1 \mathrm{H}), 8.09(\mathrm{~d}, J=1.2 \mathrm{~Hz}, 1 \mathrm{H}), 8.24(\mathrm{~s}, 1 \mathrm{H}), 8.29$ (s, 1H); IR, v (KBr disc):1553, 1472, $1420,1298,781 \mathrm{~cm}^{-1}$.

m,m'-Diiodoazoxybenzene (2d). Recrystallized from ethanol, m.p. $120-121{ }^{\circ} \mathrm{C}$ (lit. [15] $\left.118-119{ }^{\circ} \mathrm{C}\right)$; ${ }^{1} \mathrm{H}-\mathrm{NMR}\left(\mathrm{CDCl}_{3}\right): \delta 7.18-7.27(\mathrm{~m}, 2 \mathrm{H}), 7.71(\mathrm{~d}, J=7.8 \mathrm{~Hz}, 1 \mathrm{H}), 7.89(\mathrm{~d}, J=7.8 \mathrm{~Hz}, 1 \mathrm{H}), 8.08(\mathrm{~d}$, $J=9 \mathrm{~Hz}, 1 \mathrm{H}), 8.25$ (d, $J=8.1 \mathrm{~Hz}, 1 \mathrm{H}), 8.55$ (s, 1H), 8.63 (s, 1H); IR, v (KBr disc):1545, 1470, 1418, $1294,783 \mathrm{~cm}^{-1}$.

p,p'-Dibromoazoxybenzene (2e). Recrystallized from ethanol, m.p. $171-173{ }^{\circ} \mathrm{C}$ (lit. [16] $173-175{ }^{\circ} \mathrm{C}$ ); ${ }^{1} \mathrm{H}-\mathrm{NMR}\left(300 \mathrm{MHz}, \mathrm{CDCl}_{3}\right): \delta 7.62-7.69(\mathrm{~m}, 4 \mathrm{H}), 8.11(\mathrm{~d}, J=8.7 \mathrm{~Hz}, 2 \mathrm{H}), 8.21(\mathrm{~d}, J=9 \mathrm{~Hz}, 2 \mathrm{H})$; IR, $v$ (KBr disc): $1575,1465,1398,1319,826 \mathrm{~cm}^{-1}$. 
p,p'-Diiodoazoxybenzene (2f). Recrystallized from ethanol, m.p. 205-207 ${ }^{\circ} \mathrm{C}$ (lit. [16] 208-210 ${ }^{\circ} \mathrm{C}$ ); ${ }^{1} \mathrm{H}-\mathrm{NMR}\left(300 \mathrm{MHz}, \mathrm{CDCl}_{3}\right): \delta 7.74-7.81(\mathrm{~m}, 4 \mathrm{H}), 7.87(\mathrm{~d}, J=8.4 \mathrm{~Hz}, 2 \mathrm{H}), 7.98(\mathrm{~d}, J=8.4 \mathrm{~Hz}, 2 \mathrm{H})$; IR, $v$ (KBr disc): $1572,1468,1393,1321,829 \mathrm{~cm}^{-1}$.

p,p'-Dicarboxylazoxybenzene (2g). Recrystallized from DMF, m.p. $>300{ }^{\circ} \mathrm{C}$ (lit. [3] 350-353 $\left.{ }^{\circ} \mathrm{C}\right) ;{ }^{1} \mathrm{H}-$ NMR (DMSO): $\delta 8.01(\mathrm{~d}, J=7.8 \mathrm{~Hz}, 2 \mathrm{H}), 8.10-8.17(\mathrm{~m}, 5 \mathrm{H}), 8.37(\mathrm{~d}, J=8.1 \mathrm{~Hz}, 1 \mathrm{H}), 13.30(\mathrm{~s}, 2 \mathrm{H})$; IR, v (KBr disc):3421, 1690, 1603, 1460, 1423, 1292, 833; Anal. calcd. for $\mathrm{C}_{14} \mathrm{H}_{10} \mathrm{~N}_{2} \mathrm{O}_{5}$ : C, 58.74; $\mathrm{H}$, 3.52; N,9.79. Found: C,58.49; H,3.57; N,9.68.

Azoxybenzene (2h). Recrystallized from ethanol, m.p. $35-36{ }^{\circ} \mathrm{C}$ (lit. [17] $\left.35{ }^{\circ} \mathrm{C}\right) ;{ }^{1} \mathrm{H}-\mathrm{NMR}\left(\mathrm{CDCl}_{3}\right): \delta$ 7.40-7.54 (m, 6H), 8.05-8.32 (m, 4H); IR, v (KBr disc): 1572, 1474, 1425, 1329, 750, $670 \mathrm{~cm}^{-1}$.

m,m'-Dimethylazoxybenzene (2i). Recrystallized from ethanol, m.p. $35-37{ }^{\circ} \mathrm{C}$ (lit. [15] 33-35 ${ }^{\circ} \mathrm{C}$ ); ${ }^{1} \mathrm{H}-$ NMR $\left(\mathrm{CDCl}_{3}\right): \delta 2.41(\mathrm{~s}, 3 \mathrm{H}), 2.44(\mathrm{~s}, 3 \mathrm{H}), 7.18(\mathrm{~d}, J=7.2 \mathrm{~Hz}, 1 \mathrm{H}), 7.33-7.38(\mathrm{~m}, 3 \mathrm{H}), 7.96-8.09$ (m, $4 \mathrm{H})$; IR, v (KBr disc): 1603, 1493, 1458, 1414, 1306, $787 \mathrm{~cm}^{-1}$.

\section{Conclusions}

In conclusion, several nitroarenes were reduced in water to the corresponding azoxybenzenes in good yields by potassium borohydride in the presence of PEG-400 as a phase transfer catalyst. Electron-withdrawing substituents on the benzene ring facilitate the reductions. The simplicity of experimental procedure, the high efficiency of the reactions, and the utilization of water as solvent are the advantages of the present protocol.

\section{Acknowledgements}

The authors are grateful to the National Science Foundation of China (Liu, No.21072019) for the support of this work.

\section{References}

1. Weill, C.E.; Panson, G.S. The reduction of nitrobenzene to azoxybenzene by sodium borohydride. J. Org. Chem. 1956, 21, 803.

2. Hutchins, R.O.; Lamson, D.W.; Rua, L.; Milewski, C.; Maryanoff, B. Reduction of aromatic nitro compounds with sodium borohydride in dimethyl sulfoxide or sulfolane. Synthesis of azo or azoxy derivatives. J. Org. Chem. 1971, 36, 803-806.

3. Shine, H.J.; Mallory, H.E. The reduction of aromatic nitro compounds by potassium borohydride. J. Org. Chem. 1962, 27, 2390-2391.

4. Ren, P.D.; Pan, S.F.; Dong, T.W.; Wu, S.H. Reduction of aromatic nitro compounds to azoxy compounds with $\mathrm{NaBH}_{4} / \mathrm{BiCl}_{3}$ system. Acta Chim. Sinica 1998, 56, 714-718.

5. Ren, P.D.; Pan, S.F.; Dong, T.W.; Wu, S.H. Catalytic reduction of nitroarenes to azoxybenzenes with sodium borohydride in the presence of bismuth. Synth. Commun. 1996, 26, 3903-3908.

6. Siemeling, U.; Türk, T.; Vorfeld, U.; Fink, H. Selective reduction of an aromatic nitro group to an azoxy Unit in the presence of an aliphatic nitro group. Monatsh. Chem. 2003, 134, 419-423. 
7. Ohe, K.; Uemura, S.; Sugita, N.; Masuda, H.; Taga, T. Sodium arenetellurolate-catalyzed selective conversion of nitro aromatics to aromatic azoxy or azo compounds and its application for facile preparation of 3,3'- and 4,4'-bis[.beta.-(aryltelluro)vinyl] azobenzenes from (3- and 4nitrophenyl)acetylenes. J. Org. Chem. 1989, 54, 4169-4174.

8. Balasubramanian, D.; Sukumar, P.; Chandani, B. Linear unsubstituted polyethylene glycols as phase transfer catalysts. Tetrahedron Lett. 1979, 20, 3543-3544.

9. Zupancic, B.G.; Kokalj, M. Catalytic activity of polyethylene glycols in the reduction of carbonyl compounds under phase-transfer catalyzed conditions. Synth. Commun. 1982, 12, 881-886.

10. Neumann, R.; Sasson, Y. Mechanism of base-catalyzed reactions in phase-transfer systems with poly(ethylene glycols) as catalysts. The isomerization of allylanisole. J. Org. Chem. 1984, 49, 3448-3451, and references cited therein.

11. Leadbeater, N.E.; Marco, M.; Tominack, B.J. First examples of transition-metal free Sonogashiratype couplings. Org. Lett. 2003, 5, 3919-3922.

12. Yadav, G.D.; Motirale, B.G. Microwave-irradiated synthesis of nitrophen using PEG 400 as phase transfer catalyst and solvent. Org. Proc. Res. Devel. 2009, 13, 341-348, and references cited therein.

13. Huang, X.; Huang, Z.Z. New phase transfer catalyzing reagents-polyethylene glycol and its derivatives. Нuaxue Shiji 1985, 7, 20-22.

14. Huang, Z.Z.; Ye, S.; Xia, W.; Yu, Y.H.; Tang, Y. Wittig-type olefination catalyzed by PEGtelluride. J. Org. Chem. 2002, 67, 3096-3103.

15. Mckillop, A.; Raphael, R.A.; Taylor, E.C. Thallium in organic synthesis. XI. Preparation of azoxy compounds. J. Org. Chem. 1970, 35, 1670-1672.

16. Hou, Z.M.; Fujiwara, Y.; Taniguchi, H. Lanthanides in organic synthesis. Samarium metal promoted selective formation of azoxy compounds. J. Org. Chem. 1988, 53, 3118-3120.

17. Gore, P.H., Wheeler, O.H. The absorption spectra of aromatic azo and related compounds. I. azoxybenzenes. J. Am. Chem. Soc. 1956, 78, 2160-2163.

Sample Availability: Samples of the compounds are available from the authors.

(C) 2011 by the authors; licensee MDPI, Basel, Switzerland. This article is an open access article distributed under the terms and conditions of the Creative Commons Attribution license (http://creativecommons.org/licenses/by/3.0/). 